\title{
Going Gaga: Investigating, Creating, and Manipulating the Song Stuck in My Head
}

\author{
IRA E. HYMAN*, NAOMI K. BURLAND, HOLLYANN M. DUSKIN, MEGAN C. COOK, \\ CHRISTINA M. ROY, JESSIE C. MCGRATH and REBECCA F. ROUNDHILL \\ Psychology Department, Western Washington University, Bellingham, USA
}

\begin{abstract}
Summary: Having a song stuck in your head is a commonly experienced intrusive thought. We explored the intrusive song phenomenon through a survey, an experimental diary study, and three laboratory experiments. Contrary to the belief that only obnoxious songs get stuck, we found that songs people know and like frequently became intrusive. We also found that intrusive songs followed environmental cues. In addition, if a song continued to play in someone's head immediately after listening to it, the song was likely to return as an intrusive song within the next 24 hours. Similar to mind wandering, the return of intrusive songs depended on cognitive resources: people reported that intrusive songs returned during low cognitive load activities, and we found that overloading the cognitive systems with challenging activities increased intrusive song frequency. Throughout our studies, we easily created and manipulated intrusive song experiences. Songs provide a valuable method to investigate intrusive thoughts. Copyright () 2012 John Wiley \& Sons, Ltd.
\end{abstract}

Sometimes, the mind acts like a broken record-repetitively playing the same song over and over again. Having a song stuck in your head is a commonly experienced intrusive thought that occurs frequently for many people. The phenomenon has been labeled many things: an earworm (Halpern \& Bartlett, 2011; Kellaris, 2008; Levitin, 2006), imagined music (Bailes, 2007), involuntary semantic memories (Kvavilashvili \& Mandler, 2004), and involuntary musical imagery (Liikkanen, 2008, 2012a; Sacks, 2007). To make explicit the connection to other forms of intrusive thoughts, we refer to the experience as an intrusive song.

Because experiencing an intrusive song is common, several beliefs exist concerning the experience. One common belief is that annoying music is more likely to become stuck - even the frequently used term 'earworm' perpetuates the assumption that intrusive songs typically have a negative quality (Kellaris, 2008; Levitin, 2006). Other beliefs are that particular music characteristics, such as simplicity and repetitiveness, cause songs to become intrusive (Kellaris, 2008; Levitin, 2006; although see Sacks, 2007, for counterexamples) and that individual characteristics, such as musical training, neuroticism, and obsessive-compulsive disorder, relate to intrusive song experiences (Beaman \& Williams, 2010; Kellaris, 2008; Levitin, 2006; Liikkanen, 2012a; Sacks, 2007). While investigations of intrusive songs are important to understand this common experience, such studies may also provide a method to study involuntary and intrusive thoughts more generally. In essence, intrusive songs may share features with other failures to control the contents of consciousness such as involuntary memories and mind wandering.

Intrusive songs may resemble involuntary and intrusive memories in many ways (researchers have used involuntary and intrusive when referring to nonvolitional memories, and we will use the term that the original authors used because the difference between these terms has not yet been clearly defined, but see Kvavilashvili \& Schlagman, 2011, for a suggestion that repetitiveness is a defining characteristic of intrusive memories). Although there is a general belief that

*Correspondence to: Ira Hyman, Psychology Department, Western Washington University, 516 High St., Bellingham, WA 98225, USA.

E-mail: Ira.Hyman@wwu.edu intrusive memories concern negative and traumatic events, involuntary and intrusive memories can concern both positive and negative autobiographical experiences (Berntsen, 1996; Berntsen, 2001; Brewin, Christodoulides, \& Hutchinson, 1996). Likewise, there is a general belief that intrusive songs occur primarily for disliked songs (Kellaris, 2003, 2008; Levitin, 2006; Sacks, 2007). Another area of similarity is that experiencing an involuntary memory is often described as similar to reliving the original event (Berntsen, 2001). Intrusive songs may also involve a sense of reexperiencing. When people intentionally imagine music, for example, they reexperience many aspects of the music: the song replays over time (Halpern, 1988a; Halpern, 1988b), involves various aspects of the musical experience (Bailes, 2007), includes pitch information (Levitin, 1994), evokes emotion (Lucas, Schubert, \& Halpern, 2010), and involves the same brain areas as listening to music (Halpern \& Zatorre, 1999; Halpern, Zatorre, Bouffard, \& Johnson, 2004; Zatorre, Halpern, Perry, Meyer, \& Evans, 1996). The third area of similarity is that intrusive songs appear to include a repetitive quality such that they return frequently to awareness much like some instances of involuntary memories (Berntsen, 1996, 2001) and intrusive memories (Brewin et al., 1996). One other area of potential overlap between intrusive songs and involuntary memories may be the nature of cuing. Berntsen and her colleagues (Berntsen, 1996; Berntsen, 2001; Rasmussen \& Berntsen, 2009) have argued that involuntary memories generally occur in response to cues. Intrusive songs may return in a similar manner.

Intrusive songs may also share characteristics with instances of mind wandering (McVay \& Kane, 2010; Schooler, 2002; Smallwood \& Schooler, 2006). Mind wandering occurs when people lose track of what they are supposed to be focused on and start thinking of something else. If songs return during mind-wandering episodes, then intrusive songs may be dependent on cognitive load, cognitive engagement, and executive control (McVay \& Kane, 2010; Smallwood \& Schooler, 2006). Smallwood, Nind, and O'Connor (2009) found that mind wandering was more frequent during tasks that did not require constant monitoring or tasks that people did not find engaging. In a naturalistic sampling, Kane et al. (2007) found that several aspects of task engagement predicted 
mind wandering. In general, people reported more mind wandering when bored, stressed, tired, doing schoolwork, and in a busy environment. They reported less mind wandering when happy and doing a preferred activity. They also noted that as challenge of an activity increased, mind wandering increased for individuals with low working memory capacity.

Recently, several researchers have begun systematic investigations of having a song stuck in one's head. For example, researchers (Beaman \& Williams, 2010; Halpern \& Bartlett, 2011; Wammes \& Baruss, 2009) have conducted surveys concerning the general experience of having a song stuck in one's head. Beaman and Williams (2010) and Halpern and Bartlett (2011) also conducted diary studies in which people recorded particular instances of intrusive songs for several days. Kvavilashvili and Mandler (2004) conducted a survey and diary study concerning involuntary semantic memories and found that many of these memories involved songs. Williamson et al. (2012) reported survey responses concerning one issue-the circumstances related to the origin of intrusive song experiences.

Liikkanen (2008, 2012a, 2012b) has reported on a large scale survey and attempted induction of intrusive songs in three papers. Because Liikkanen asked about intrusive thoughts generally and attempted intrusive song induction in the same sample, his results are difficult to interpret. People were first asked about their musical background, then asked to recall song lyrics from five very different songs as a method of inducing intrusive songs, next reported on intrusive thoughts including involuntary music, and finally asked if any of the songs for which they had attempted lyric retrieval were stuck in their heads. Thus, recalling lyrics may have influenced answers on the involuntary music survey (the data reported in Liikkanen, 2012a), and the intrusive thought survey could have influenced whether people continued to think about the lyrics they had just attempted to recall (the data reported in Liikkanen, 2012b), although he was not clear in noting the possible interaction of the various tasks.

There are some points of agreement from these studies and several issues that remain unclear concerning intrusive songs. One consensus finding is that almost everyone has experienced an intrusive song with many people claiming they frequently have songs stuck in their heads (Bailes, 2007; Beaman \& Williams, 2010; Halpern \& Bartlett, 2011; Kvavilashvili \& Mandler, 2004; Liikkanen, 2008, 2012a, 2012b).

Another area of clear agreement is that people report a great variety of songs having been stuck (Beaman \& Williams, 2010; Halpern \& Bartlett, 2011; Liikkanen, 2012a; Williamson et al., 2012). This contradicts claims that particular characteristics, such as simplicity and repetitiveness, result in a small set of songs frequently becoming stuck for many people (Kellaris, 2008; Levitin, 2006). Instead, we suspect that intrusive songs may reflect the listening habits of individuals because Williamson et al. (2012) reported that musical cues frequently contributed to intrusive songs and Halpern and Bartlett (2011) found more Christmas songs became stuck when they conducted data collection during the holiday season.
The role of individual differences is less clear (Beaman \& Williams, 2010). Beaman and Williams (2010) found that musical training was not related to intrusive song experiences, but they noted that people who reported music was more important claimed longer lasting intrusive song experiences. In contrast, Liikkanen (2012a) found that people with extensive musical practice claimed more frequent and longer lasting intrusive song experiences. Liikkanen (2012a) also reported that women reported more intrusive song experiences than men, but Beaman and Williams (2010) found no difference between men and women.

Another area of contention concerns the myth that only obnoxious music becomes intrusive. Both Beaman and Williams (2010) and Halpern and Bartlett (2011) found that people generally like the songs that recur as intrusive songs and generally report liking the experience of having a song stuck in their heads. In contrast, Liikkanen (2012a) reported that although people primarily feel neutral about the songs in their heads, they also rated intrusive songs as the most disturbing type of involuntary memories. Liikkanen's effects, however, may reflect the attempted musical induction that included some songs that may not have been popular with the sample (Liikkanen, 2012b).

Research concerning how intrusive song experiences begin has also resulted in potentially inconsistent findings. Williamson et al. (2012) explicitly asked about how peoples' experiences began. They found that various musical cues were the most common cause. Additionally, people frequently reported being in low attention states at the time when a song became stuck. Overall, Williamson and colleagues reported no instances in which people were unable to report the origin of their intrusive song experiences, but this may reflect a limitation in their retrospective sampling method because many individuals did not complete all questions. In contrast, Kvavilashvili and Mandler (2004) conducted a diary study and found that people frequently were unable to report the genesis of involuntary semantic memories, including songs. They argued that this distinguished involuntary semantic memories from involuntary autobiographical memories because people can generally report the cause of those memories.

In this paper, we report five studies concerning intrusive songs: a survey, an experimental diary study, and three lab experiments. In our survey, we sought to describe intrusive song experiences. We were interested in the cues that cause intrusive songs, the circumstances in which songs return, the nature of reexperiencing, and whether liked or disliked songs more commonly became intrusive. In contrast with most existing surveys, we asked not only about the experience in general but also about individuals' most recent experiences.

In our other studies, we developed experimental methodologies for the investigation of intrusive songs. In many ways, our method is based on early studies of priming the contents of consciousness (Antrobus, Singer, \& Greenberg, 1966; Becker, Horowitz, \& Campbell, 1973; Holmes \& Bourne, 2008; Horowitz \& Becker, 1971; Horowitz \& Becker, 1973, 1973; Klos \& Singer, 1981; McVay \& Kane, 2010). In both the diary study and experiments, we played songs and then checked to see if the songs remained in and 
returned to consciousness. Using these methods, we investigated some factors that may influence the occurrence of intrusive songs. We manipulated whether the songs were played to completion or interrupted. We predicted that interrupting the song would create a sense of incompleteness and lead the song to remain active in consciousness, potentially demonstrating a Ziegarnik effect. In addition, we manipulated the difficulty level and nature of the task that followed music presentation to see if intrusive songs returned on the basis of cognitive load.

\section{STUDY 1: INTRUSIVE SONG SURVEY}

To develop a richer description of intrusive songs, we asked individuals about their most recent experience of having a song stuck in their heads. Like other researchers, we asked about the causes intrusive songs, whether intrusive songs are liked and well known, and the frequency of intrusive song experiences. We also asked several questions about the nature of reexperiencing-particularly the experience duration, how continuous the experience was, which part of the song was repeating, and which aspects of the music were playing in peoples' heads. In the existing survey reports, researchers have reported conflicting findings concerning whether people like intrusive songs and concerning individual differences that may be related to intrusive songs (Beaman \& Williams, 2010; Halpern \& Bartlett, 2011; Liikkanen, 2012a). Thus, we also looked for gender differences and differences based on musical training. Unlike earlier surveys that asked about the general experience of having a song stuck in one's head (Beaman \& Williams, 2010; Halpern \& Bartlett, 2011; Liikkanen, 2012a), we asked about both the general experience and the most recent experience. Recollections of a recent experience may be more reliable than beliefs concerning an experience in general.

\section{Method}

\section{Participants}

Participants were recruited using the snowball method. We e-mailed the survey link to friends and posted it online. Participants were encouraged to forward the link to others. During a 2-week period, 299 people participated (72 men, 222 women, 5 with gender information missing; ages from 18 to $75, M=30.13, S D=13.88,10$ with age information missing).

\section{Materials and procedure}

Participants completed a 19-question survey at surveymonkey. com. After reading a short consent form, participants answered 10 questions about their most recent intrusive song experience, including when the most recent experience occurred, which song was involved, how long the experience lasted, how constant it was, how much of the song repeated, if the song was annoying or liked, how frequently they heard the song, how well they knew it, what they thought triggered the experience, and how the song was reexperienced in their heads. Table 1 includes response options and participant response distributions.
Table 1. Distribution of responses to the intrusive song survey

\begin{tabular}{|c|c|}
\hline Question and response options & Percentag \\
\hline \multicolumn{2}{|l|}{ When have you had a song stuck in your head? } \\
\hline Right now & 30.8 \\
\hline Earlier in the day & 23.4 \\
\hline Sometime in the last few days & 34.1 \\
\hline Sometime in the last few weeks & 7.4 \\
\hline At some time in my life & 4.3 \\
\hline \multicolumn{2}{|l|}{ How long has the song been stuck in your head? } \\
\hline A few minutes & 24.6 \\
\hline A few hours & 41.1 \\
\hline A few days & 24.2 \\
\hline Many days or longer & 10.1 \\
\hline \multicolumn{2}{|l|}{$\begin{array}{l}\text { How constant is your experience of this song being stuck } \\
\text { in your head? }\end{array}$} \\
\hline You have been constantly hearing it & 9.6 \\
\hline You hear the song sometimes & 51.0 \\
\hline The song can go away for hours but keeps coming back & 39.4 \\
\hline \multicolumn{2}{|l|}{ How much of the song repeats in your head? } \\
\hline One or two lines from the chorus & 54.6 \\
\hline One or two lines from a verse & 16.6 \\
\hline A larger part of the song & 16.6 \\
\hline Most or all of the song & 8.5 \\
\hline Only the music with no lyrics & 3.7 \\
\hline \multicolumn{2}{|l|}{ Do you find the song annoying or do you like it? } \\
\hline Very annoying & 4.1 \\
\hline Annoying & 7.5 \\
\hline A little annoying & 17.3 \\
\hline Like it a little & 17.7 \\
\hline Like it & 29.6 \\
\hline Like it a lot & 23.8 \\
\hline
\end{tabular}

How frequently do you hear the song on the radio or some other music playing device?

Many times a day

A few times a day

A few times per week

A few times per month

Very rarely

How well do you know the song?

Not very well

You can sing or hum along with part of the song

You can sing or hum along with most of the song

You know the whole song completely

How did the song get stuck in your head?

You don't know

You heard all or part of the song

You heard a phrase that brought the song to mind

You had an emotional experience that reminded you of the song

Other

When the song is in your head, how do you experience it? (check all that apply)

Lyrics

Melody

The singer's voice

Instruments and background music

The beat

Your own voice singing along

Images of any sort

You see the video for the song

How frequently do you get songs stuck in your head?

Almost never

A few times per month

A few times per week

A few times every day

Constantly have a song playing in your head

Is there any one song that frequently gets stuck in your head?

No

Yes 
Participants then responded to six questions about their general music experience: how frequently they experience intrusive songs, if there is a particular song that frequently gets stuck, how frequently they listen to music, their favorite types of music, if they generally sing, hum, or whistle along with music, and if they play any instruments. Lastly, participants answered basic demographic questions.

\section{Results and discussion}

We begin by describing individuals' most recent intrusive song experience (see Table 1). First, an individual's connection to a song predicted which songs became intrusive. We found that people generally knew the intrusive song well. In addition, nearly two-thirds of the respondents liked the song stuck in their heads, replicating most other surveys (Beaman \& Williams, 2010; Halpern \& Bartlett, 2011). This conflicts with the myth that intrusive songs are mainly comprised of annoying music (Kellaris, 2008; Levitin, 2006) and with Liikkanen's (2012a) finding that most people report feeling neutral about intrusive songs. Although annoying songs may become intrusive, this appears to be relatively rare.

Another important aspect of intrusive songs is that they are generally unique to the individual. For $75.1 \%$ of our respondents, their intrusive song was unique to them. Only $24.9 \%$ experienced the same intrusive song as at least one other respondent. Furthermore, only nine songs were reported by more than two individuals. The frequently reported songs were generally popular when the survey was conducted. For example, four different songs by Lady Gaga were reported by two or more individuals. Overall, the variety of songs reported indicates that any song can potentially become stuck in someone's head.

In terms of the intrusive song experience, most people reported an experience that occurred on the day they responded or during the previous few days. The song had typically been intrusive for hours or days but was experienced intermittently rather than continuously. Usually, only a few lines were repeating, typically from the chorus. People indicated that they reexperienced many aspects of the song, including the lyrics, melody, and singer's voice. Only $22 \%$ of respondents indicated that they had one particular song that frequently recurred intrusively.

Recent music exposure was the most frequently checked genesis of intrusive song experiences. This replicates both Kvavilashvili and Mandler (2004) and Williamson et al. (2012). Similar to Kvavilashvili and Mandler, many people reported that they did not know the cause of their intrusive song experience. These findings would be consistent with Kvavilashvili and Mandler's argument that some forms of involuntary memories reflect priming by the item itself, that is, being recently exposed to the song. They suggested potentially a meaningful difference between this repetition priming instigation of involuntary thoughts and involuntary memories caused by other triggers such as lines from the song, artist names, and emotional states.

We looked to see if any aspects of the limited demographics we collected were related to characteristics of intrusive song experiences. Both Kellaris (2003) and Liikkanen (2012a) reported gender differences in how intrusive songs were experienced, whereas Beaman and Williams (2010) failed to find any differences. We generally found no gender differences. The only difference we observed was that men reported liking their most recent intrusive song $(M=4.68, S D=1.44)$ more than women $(M=4.21, S D=1.38), t(289)=2.458$, $p=.015, d=0.33$.

We also examined differences between musicians (people who play at least one musical instrument) and nonmusicians. Other researchers have suggested that musicians may have more frequent or distinctive intrusive song experiences (Kellaris, 2003; Levitin, 2006; Liikkanen, 2012a), although Beaman and Williams (2010) failed to find any differences. Musicians reported having intrusive song experiences more frequently than nonmusicians, $\chi^{2}(2, \quad N=292)=12.639$, $p=.002$, and that their described experience had occurred more recently, $\chi^{2}(4, N=294)=9.797, p=.044$ (see Table 2). In addition, $70.1 \%$ of musicians claimed to know the song very well or completely compared with only $54.1 \%$ of nonmusicians, $\chi^{2}(2, N=293)=7.917, p=.005$. Musicians also reported reexperiencing more aspects of the song $(M=3.64, \quad S D=1.81)$ than nonmusicians $(M=3.16$, $S D=1.70), t(292)=2.336, p=.020, d=0.28$. We found no differences in the experience length, how constant the experience was, what part of the song was repeating, how the song got stuck, or if one particular song frequently became intrusive.

We also found that people who listen to music constantly or for a large part of the day reported more frequent intrusive song experiences than people who listen less often, $\chi^{2}(4, N=293)=21.628, p<.001$. This may be consistent with Beaman and Williams (2010) observation that people who report music as more important have more frequent intrusive song experiences. The onset of intrusive song cycles may reflect opportunities presented by music exposure, indicating that environmental cues play a role in intrusive songs similar to their role in other involuntary memories (Kvavilashvili \& Mandler, 2004; Williamson et al., 2012).

We found that people describing an earlier intrusive song experience liked the song less $(M=4.10, S D=1.50)$ than people describing a current experience $(M=4.52$, $S D=1.31), t(292)=2.578, p=.010, d=0.30$. For this reason, we suggest that the myth of obnoxious songs becoming intrusive may reflect a memory bias. Perhaps, negative intrusive songs are more memorable or better match beliefs

Table 2. The frequency of intrusive songs and timing of the recent experience for musicians and nonmusicians

Musicians (\%) Nonmusicians (\%)

Frequency of intrusive songs

\begin{tabular}{lrr} 
Rarely & 25.6 & 39.0 \\
Few times per week & 37.3 & 37.7 \\
Daily/constantly & 42.1 & 23.3 \\
Timing of most recent & & \\
Current & 35.8 & 25.0 \\
Some time today & 23.9 & 23.8 \\
Last few days & 34.3 & 33.8 \\
Last few weeks & 3.7 & 10.6 \\
At some time in life & 2.2 & 6.3 \\
\hline
\end{tabular}


about intrusive song experiences. Thus, if people do not have an easily retrievable experience, they may find a memory that fits with the prevailing cultural belief.

\section{STUDY 2: INTRUSIVE SONG EXPERIMENTAL DIARY STUDY}

Following our survey findings, we developed a method for inducing intrusive song experiences. Our diary study was also based on earlier work on influencing the contents of consciousness (Antrobus et al., 1966; Becker et al., 1973; Horowitz \& Becker, 1971; Horowitz \& Becker, 1973, 1973; Klos \& Singer, 1981). In those studies, researchers presented potentially stressful or arousing ideas such as stressful films (Becker et al., 1973; Horowitz \& Becker, 1971), erotic films (Horowitz \& Becker, 1973, 1973), and parent conflict stories (Klos \& Singer, 1981). These researchers then monitored participants' thoughts and found frequent intrusive thoughts. We played songs at the end of a seminar and recorded if the songs continued playing in individuals' heads immediately after class and if they returned as intrusive songs before the next class session. We also played half of the songs completely and truncated the other songs in the second chorus.

We predicted that songs participants knew and liked would be more likely to remain in consciousness after class and more likely to return as intrusive songs. The prediction was based on our survey findings and those of other researchers (Beaman \& Williams, 2010; Halpern \& Bartlett, 2011). Of course, liking a song may not be the direct cause of why a song gets stuck in someone's head. Instead, people may listen to songs they like, and therefore, opportunity may be the proximate cause of intrusive song experiences. In that case, we may find no effect of knowing and liking songs.

We also looked for possible Zeigarnik effects in this study. Zeigarnik effects reflect unfinished activities and thoughts staying active in memory and consciousness longer than completed thoughts. Klos and Singer (1981) reported that conflicts without closure were more likely to remain active in consciousness. In her original study, Zeigarnik (1967) gave participants several tasks and only allowed them to complete some. Generally, interrupted tasks were better remembered. She argued that people keep incomplete tasks mentally active on the basis of a need to complete the tasks. In our study, a Zeigarnik effect could appear in two ways. First, songs that were cut during the chorus could be more likely to return as intrusive songs. In this case, the Zeigarnik effect would reflect the lack of completion on the basis of the experimental manipulation. Second, if a person reports that a song continued playing in their head immediately after class, then that song could be more likely to return. This second aspect of a Zeigarnik effect is not the typical presentation of Zeigarnik effects because that focuses on an experimental interruption. Nonetheless, the mental failure to complete was clearly the focus of Zeigarnik in her original research. She noted that the actual experimental interruptions did not always result in improved memory. Instead, she stated that the memories 'persist if the task has not been completed to the subject's own satisfaction regardless of whether this is equivalent to what may seem from another's inspection to constitute finished or unfinished' (p. 313). If the song starts playing in someone's head, the song would be an active thought, and individuals would be unlikely to complete the thought because people typically report that only small parts of songs repeat in their heads as intrusive songs and people are generally unable to remember entire songs (Hyman \& Rubin, 1990; Rubin, 1995).

\section{Method}

\section{Participants}

Sixteen upper-level psychology undergraduate students (13 women, 3 men) conducted this study as researcherparticipants. Their ages ranged from 21 to $26(M=22.19$, $S D=1.81)$. The students were involved in the project as part of a cognition seminar focused on consciousness and were familiar with the concepts being studied.

\section{Materials and procedure}

Participants listened to a song at the end of each class meeting during the middle of the academic term (18 total songs). Songs were chosen through class discussion. With the Study 1 findings, the students selected songs that were generally known and liked (although given the variety of listening preferences, no songs were uniformly known and liked). Songs were presented using YouTube.com. Although not every participant heard every song because of absences, all participants were present for the majority. The songs were either played completely or interrupted during the second chorus. The researcher-participants abstained from listening to other music for at least 30 minutes after each class.

At the beginning of the next class session, participants completed an intrusive song survey. First, they reported how well they knew and liked the song. Participants then indicated whether they continued to mentally hear the song after it had stopped playing in class and whether it returned as an intrusive song. If the song returned, they indicated how frequently the intrusive song recurred, which section of the song was replaying, and the activity in which they were engaged when the song returned (e.g., walking, studying, or driving). They also noted whether or not they had been thinking about the class when the song returned.

\section{Results and discussion}

We found that songs people knew and liked more often became intrusive songs, extending the findings of Study 1 . For each person, we calculated the percentage of songs they continued to mentally replay immediately after class and the percentage that returned during the ensuing few days. After class, people continued mentally hearing songs that they knew well $(M=61.35, S D=33.82)$ more often than songs they did not know well $(M=40.64, S D=35.93), \quad t(15)=2.390$, $p=.030, d=0.60$. Additionally, individuals had more songs they knew well $(M=54.68, S D=20.09)$ return before the next class session than songs they did not know well $(M=16.89$, $S D=29.02), t(15)=6.121, p<.001, d=1.51$.

Similarly, we found that people continued mentally hearing songs after class that they liked $(M=61.64, S D=30.65)$ more frequently than songs they did not like $(M=43.45$, 
$S D=27.19), t(15)=2.742, p=.015, d=0.69$. Songs that people liked $(M=55.15, S D=24.89)$ also returned more often before the next class than songs they did not like $(M=29.45$, $S D=24.44), t(15)=3.261, p=.005, d=0.82$. Knowing and liking ratings were positively correlated for each individual, and the average correlation $(r=.55, S D=0.20)$ was different from zero $(t(15)=10.871, p<.001)$. Thus, we are unclear about the relative contributions knowing and liking songs make to the onset of intrusive song experiences.

Figure 1 shows the percentage of individuals who had at least one song return during several different activities. Many of these activities reflect low cognitive load, such as walking, exercising, or daily routines, which may encourage mind wandering (Schooler, 2002; Smallwood \& Schooler, 2006) and which is consistent with the finding of Williamson et al. (2012) that songs return during low attention states. Doing schoolwork, however, was the most commonly noted activity for the return of intrusive songs. Schoolwork may encourage mind wandering but may have additionally provided a cue because the songs were associated with a class. Participants noted they had been thinking of the class $65.8 \%$ of the times when a song returned. In sum, we found that intrusive songs may return at both ends of the cognitive load continuum: during low cognitive load activities (e.g., walking) and during mentally challenging activities (e.g., schoolwork).

We also investigated whether songs that were interrupted would be more likely to return as intrusive songs. This would be consistent with a Zeigarnik effect in which interrupted activities remain active in thought. We found no difference between interrupted $(M=45.18, S D=21.98)$ and completed songs $(M=38.64, S D=21.21)$ in the percentage that returned, $t(15)=1.216, p=.243, d=0.30$.

Nonetheless, we found other evidence of a Zeigarnik effect on the basis of whether the music started playing in someone's head immediately after hearing a song and thus was personally unfinished-Zeigarnik's theoretical explanation of her effect. When people continued to mentally hear songs as they left the class $(M=66.45$, $S D=20.90$ ), the songs were more likely to return before the next class than when they did not continue to hear the songs $(M=13.66, \quad S D=23.37), \quad t(13)=7.675, \quad p<.001$, $d=2.05$. When a song starts playing in someone's head, the song is likely to return later as an intrusive song.

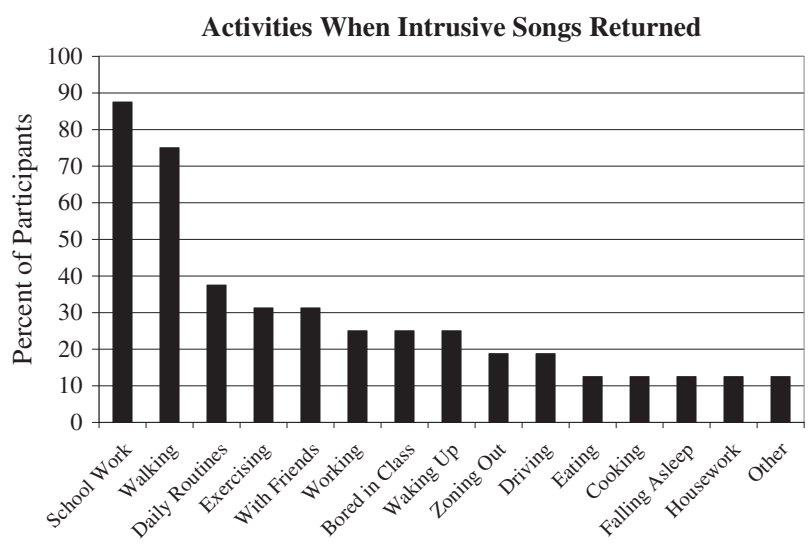

Figure 1. Activities when intrusive songs returned

\section{STUDY 3: INTRUSIVE SONG EXPERIMENT}

Study 3 was our first laboratory experiment inducing intrusive songs. One primary goal was to induce intrusive songs without participants being aware that was the goal. Both in our experimental diary study (Study 2) and Liikkanen's (2012b) online research, participants were aware that the researcher was concerned with intrusive thoughts in general and songs in particular. In this study, we asked people to evaluate a set of materials that might be used in future studies. Participants first evaluated three songs, and then, they engaged in an apparently unrelated task: completing and rating mazes. After working on the mazes, participants reported the extent to which they heard the songs playing in their heads while completing the mazes. We also surveyed the participants 24 hours later to see if the songs returned as intrusive songs.

As with our experimental diary study, we investigated possible Zeigarnik effects. We varied whether or not the last song was played completely. In the diary study, we may have failed to obtain a Zeigarnik effect on the basis of interrupting the songs because different songs were cut and played completely. Thus, whether people knew and liked the songs could have overwhelmed the possible Zeigarnik effect of interrupting songs. In this experiment, we used a consistent set of songs and manipulated completion as a between-subjects variable. We also used a 24-hour follow-up to potentially replicate the Zeigarnik effect on the basis of unfinished thoughts we observed in the diary study. We investigated whether people who heard a song playing during the mazes were more likely to have that song return during the following 24 hours. This would again constitute a Zeigarnik effect on the basis of the personal sense of the song being unfinished because they would be unlikely to complete the songs in their heads.

In this study, we also looked for order effects in whether songs played in someone's head during the maze task and whether they returned as intrusive songs. Liikkanen (2012b) suggested that recency may contribute to intrusive songs. Because Liikkanen used very different songs in his attempted induction, recency effects were hard to discern: he failed to find them in one set of his data and found a small effect in a second set of data. Nonetheless, we expected recency effects in this experiment because people frequently report recent music exposure as a cause of intrusive song experiences (Williamson et al., 2012).

\section{Method}

\section{Participants}

A total of 89 lower-level undergraduate psychology students at Western Washington University (27 men, 62 women) participated in this study to fulfill a research requirement. The participants ranged in age from 18 to $53(M=19.96$, $S D=4.06)$.

\section{Materials and procedure}

Individuals were told they were participating in a screening experiment for materials to be used in future studies. First, the participants listened to and rated three songs. Half of 
the participants listened to recent songs by female recording stars that had reached the Billboard Hot 100 chart top ten ('You Belong with Me' by Taylor Swift, 'Bad Romance' by Lady Gaga, and 'Single Ladies' by Beyonce). The other participants listened to three songs by The Beatles ('She Loves You', 'Can't Buy Me Love', and 'I Wanna Hold Your Hand'). We used different sets of known and liked songs to insure that the effects are not dependent on the type of music or current popularity. The first song stayed the same ('You Belong with Me' or 'She Loves You'), but the order of the two last songs was alternated. We also manipulated whether the final song was interrupted during the second chorus or played completely.

As the participants listened to each song, they rated how well they knew the song, how much they liked it, how frequently they heard it, how distracting it is, and how catchy it is. After the final song, participants completed simple mazes for 5 minutes and rated each for difficulty. The participants then responded to the intrusive song survey. They were asked whether any of the songs were replaying in their head during the maze task, what percentage of the time each song was playing in their head during the maze task, and which part of the song they were reexperiencing.

Finally, participants were asked to provide their e-mail address if they would be willing to respond to follow-up questions the next day. If permission was given, a follow-up survey was sent asking if any of the songs had returned to their minds during the ensuing 24 hours. Most participants agreed to be surveyed $(n=73)$, but only 36 responded to the e-mail request for additional information.

\section{Results and discussion}

We first looked to see if either the type of music (contemporary female artists vs Beatles) or which song was used as the final song influenced whether people heard the songs in their head during the maze task or reported intrusive songs on the 24-hour follow-up. We found no effects of music type or last song. Participants were equally likely to have Beatles' songs and contemporary pop songs in their heads.

We found that song order affected the percentage of time participants reported songs mentally replaying during the maze task, $F(2,176)=52.930, M S E=724.238, p<.001$, partial $e t a^{2}=.376$. Tukey's comparisons indicated that the third song replayed more $(M=43.37, S D=38.52)$ than either the first $(M=6.40, S D=16.18)$ or second song $(M=8.54$, $S D=18.50)$. Participants varied in the number of songs that they reported mentally replaying during the maze task: $24.7 \%$ reported that no songs replayed, $41.6 \%$ reported only one song (usually the third), $19.1 \%$ reported that two songs replayed for some period, and $14.6 \%$ reported that all three songs replayed for some portion of the maze task.

We also found that song order influenced whether or not the song returned during the 24 hours after the experiment, $F(2,70)=13.670, M S E=0.185, p<.001$, partial $e^{2} a^{2}=.281$. The third song $(M=0.67, S D=0.48)$ was more likely to return as an intrusive song than either the first $(M=0.22$, $S D=0.42)$ or the second song $(M=0.19, S D=0.40)$.

As with Study 2, we looked for evidence of a Zeigarnik effect, both in terms of interrupting the third song and whether having a song start replaying mentally leads to later intrusive song experiences. We found no difference in the percentage of individuals who reported reexperiencing the third song during the maze task for interrupted $(65.2 \%)$ and completed $(72.1 \%)$ songs, $\chi^{2}(1, N=89)=0.487, p=.485$. Replicating Study 2, we found that if participants continued to mentally hear the third song during the maze task, then it was more likely to return during the following 24 hours (75.9\%) than if they had not heard it during the maze task $(28.6 \%), \chi^{2}(1, N=36)=5.675, p=.017$. If a song gets started playing in someone's head, it is likely to return as an intrusive song. If the song starts playing, it may be an unfinished thought because people are unlikely to completely reconstruct the song in their heads (Hyman \& Rubin, 1990; Rubin, 1995).

\section{STUDY 4: TASK DIFFICULTY INFLUENCES THE OCCURRENCE OF INTRUSIVE SONGS}

In this study, we used the experimental method developed in Study 3 to investigate the role of cognitive load. As with Study 3, participants listened to and rated three songs (again using Beatles songs and songs by contemporary female artists). For the next task, participants worked on Sudoku puzzles. We used Sudoku puzzles because the task is generally nonverbal like mazes and the difficulty can be manipulated. We varied whether the puzzles were very easy or challenging.

If intrusive songs are similar to mind-wandering episodes, cognitive load should play an important role (McVay \& Kane, 2010; Smallwood \& Schooler, 2006). Mind wandering may occur more frequently at both ends of the cognitive load continuum. When people are engaged in easy, automatic, and uninteresting tasks, they frequently mind wander (Smallwood et al., 2009). On the other hand, people also mind wander when stressed, engaged in challenging work, reading difficult passages, and in busy environments (Kane et al., 2007), and when less engaged in the cognitive task (Smallwood et al., 2009). Consistent with mind-wandering reports, participants in our diary study reported songs returning both during low cognitive load activities and during studying.

In this experiment, we predicted that the easy Sudoku puzzles would present an appropriate level of challenge for participants. Thus, participants should stay focused and experience less time with the songs mentally replaying in their heads. In contrast, we expected that the challenging puzzles would prove too difficult and that participants would perform the puzzles less well. In this case, participants would frequently be unable to find answers and thus leave more cognitive resources available for intrusive songs.

\section{Method}

\section{Participants}

A total of 139 (46 men, 92 women, and 1 no response) lower-level undergraduate psychology students at Western Washington University participated in this study as one method of meeting a research requirement. The participants ranged in age from 18 to $23(M=19.08, S D=1.35)$. 


\section{Materials and procedure}

The procedure was similar to Study 3. Participants listened to and rated three songs, completed a puzzle task, and then reported the extent to which the songs played mentally during the puzzle task. We again asked permission to send a follow-up questionnaire 24 hours after the experiment.

We used the same three Beatles' songs as Study 3 but changed our contemporary pop songs for the enjoyment of the individuals collecting the data ('You Belong with Me' by Taylor Swift, 'Just Dance' by Lady Gaga, and 'SOS' by Rihanna). As with Study 3, we counterbalanced which song appeared in the third position. In this study, however, all songs were played completely.

In this study, individuals worked on Sudoku puzzles rather than simple mazes and did so for 10 minutes rather than 5. Half of the participants were given very easy Sudoku puzzles, and the others were given challenging puzzles. The difficulty of the puzzles was determined by the number of squares left blank for participants to complete. Participants were provided four puzzles but rarely worked on more than two. They rated each puzzle on which they worked for difficulty from 1 (easy for me) to 7 (hard for me). Mean difficulty ratings and the number of correct and incorrect answers were recorded. All other aspects of the procedure from Study 3 were kept the same.

\section{Results and discussion}

We first looked at the performance on and ratings of the Sudoku puzzles. We found these manipulation checks confirmed the differences between the very easy and challenging puzzles. The participants who worked on the easy puzzles rated the puzzles as easier $(t(137)=6.249, p<.001$ Cohen's $d=1.08$ ) and completed more correct answers than the participants who worked on the challenging puzzles $(t(137)=7.486, p<.001$ Cohen's $d=1.31)$. There was no difference in the number of errors $(t(137)=0.880$, $p=.380$ Cohen's $d=0.15)$. Table 3 presents the means for the easy and challenging puzzle conditions.

We investigated the role of song order and Sudoku difficulty in a $3 \times 2$ mixed-model analysis of variance (ANOVA) using as our dependent measure the percentage of time participants reported songs mentally replaying during the Sudoku task. We found a main effect of song order $(F(2,274)=59.038, M S E=661.136, p<.001$, partial

Table 3. Performance on the Sudoku puzzles and anagrams in the very easy and challenging conditions for Studies 4 and 5

\begin{tabular}{lcc}
\hline Study 4 & \multicolumn{2}{c}{ Sudoku condition } \\
\hline & Very easy & Challenging \\
\hline Average Sudoku rating & $3.91(1.69)$ & $5.47(1.22)$ \\
Correct answers & $54.11(30.63)$ & $21.78(18.78)$ \\
Incorrect answers & $3.49(13.30)$ & $5.13(8.07)$ \\
Study 5 & Anagram & Condition \\
& Very easy & Challenging \\
Anagram rating & $3.13(1.46)$ & $5.22(1.36)$ \\
Correct answers & $91.90(20.53)$ & $30.60(18.36)$ \\
Incorrect answers & $1.00(1.24)$ & $1.70(1.69)$ \\
Skipped anagrams & $14.02(12.00)$ & $54.02(30.81)$ \\
\hline
\end{tabular}

$\left.e t a^{2}=.301\right)$, a main effect of Sudoku difficulty $(F(1$, $137)=6.119, M S E=595.567, p=.015$, partial $\left.e t a^{2}=.043\right)$, and a significant interaction $(F(2,274)=6.580, M S E=$ 661.136, $p=.002$, partial $\left.e t a^{2}=.046\right)$. We investigated the interaction using Tukey's simple effects comparisons $(p<.05)$. For both easy and challenging Sudoku puzzles, we replicated our song order effect such that the third song was replaying in participants' heads for a greater percentage of the puzzle time than either the first or second songs. In addition, participants in the challenging condition reported the third song replaying for a greater percentage of the time than participants in the easy condition, whereas there were no differences between the challenging and easy conditions for the first and second songs (see Figure 2(a) for the means). Participants were successful in solving the easy Sudoku puzzles and experienced less intrusive mental music. In contrast, participants experienced more difficulty with the challenging puzzles and may have had more cognitive resources remaining for intrusive songs.

We also replicated Study 3 in terms of responses to the 24-hour follow-up survey. Fifty participants responded to the follow-up survey. We found that if participants reported the third song replaying during the Sudoku puzzles, they were more likely to have the song return as an intrusive song $(55.3 \%)$ than if they had not had the song replaying mentally during the puzzles (16.7\%), $\chi^{2}(1, N=50)=5.469, p=.019$. This is evidence for a Zeigarnik effect such that if an intrusive thought gets started in someone's head, it is likely to return after a short period.

(a)

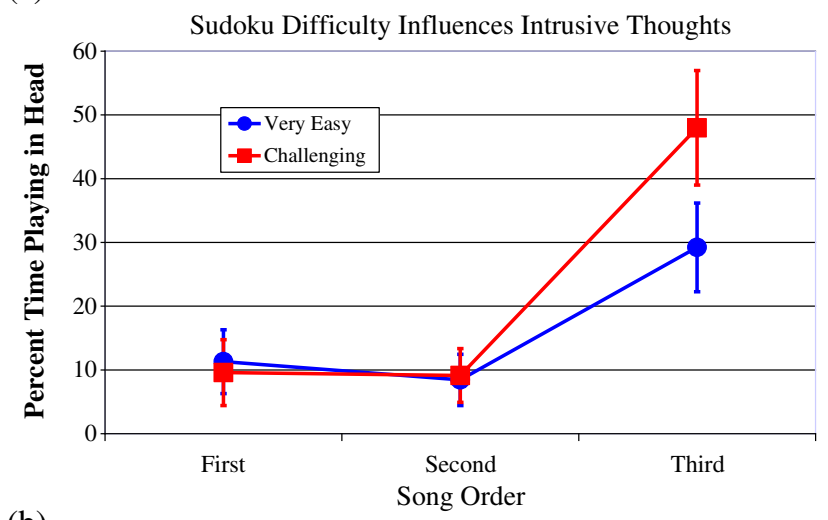

(b)

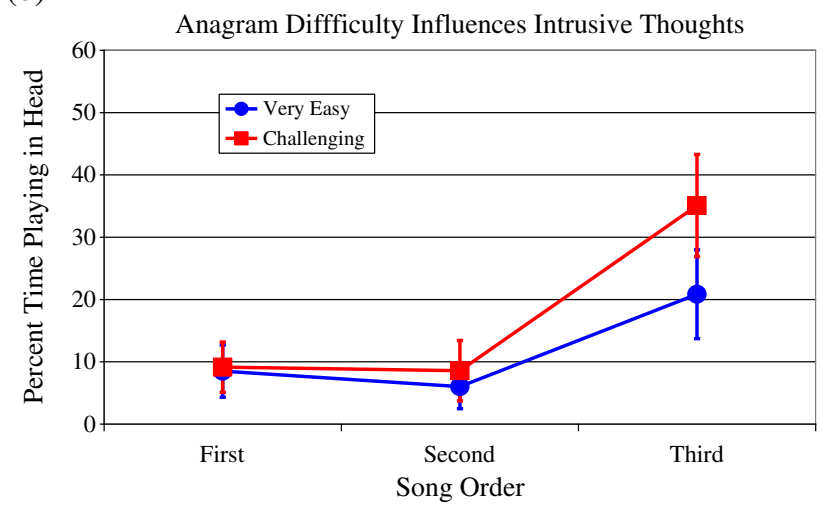

Figure 2. Cognitive load influences intrusive songs in Studies 4 and 5 (error bars are $95 \%$ confidence intervals) 


\section{STUDY 5: VERBAL TASK DIFFICULTY INFLUENCES THE OCCURRENCE OF INTRUSIVE SONGS}

Study 5 was a replication and extension of the role of cognitive load in the return of intrusive thoughts. In both of our experimental studies of intrusive songs, we used nonverbal tasks following the presentation of music. In this study, we replicated Study 4 precisely but changed to a verbal cognitive task-either easy or challenging anagrams. Smith, Wilson, and Reisberg (1995) found that covert speech disrupts auditory imagery. They argued that many auditory imagery tasks must rely on the phonological loop aspect of working memory. Thus, we hypothesized that engaging in a verbal task would decrease the occurrence of intrusive songs because both would be dependent on the phonological aspect of working memory. We also predicted that intrusive songs would be more common when participants attempted challenging anagrams, struggled to successfully complete them, and left more cognitive resources open for mental music.

\section{Method}

\section{Participants}

A total of 123 (35 men, 88 women) lower-level undergraduate psychology students at Western Washington University participated in this study as one method of meeting a research requirement. The participants ranged in age from 18 to 23 $(M=19.43, S D=1.69)$.

\section{Materials and procedure}

The procedure was a direct replication of Study 4. Participants listened to and rated three songs, completed a puzzle task, and then reported the extent to which the songs replayed in their heads during the puzzle task. We used the exact same songs as in Study 4 and subjects worked at the puzzle task for 10 minutes in this study as well. The exact replication allows some comparison of the pattern of results across studies.

In this study, participants work to solve either very easy or challenging anagrams. We used 120 five-letter anagrams based on those used by Kelley and Jacoby (1996). In the very easy condition, we switched the position of one pair of letters, typically in the middle of the word. In the challenging condition, we used the same words but switched the position of two pairs of letters. When participants finished working on the anagrams, they rated the overall difficulty from 1 (easy for me) to 7 (hard for me).

\section{Results and discussion}

We first looked at performance on the anagram task to make sure that there were meaningful differences between the very easy and challenging anagrams. Participants in the very easy condition rated the anagrams as easier $(t(121)=8.225$, $p<.001$ Cohen's $d=1.48)$, completed more anagrams successfully $(t(121)=17.474, p<.001$ Cohen's $d=3.15)$, made fewer errors $(t(121)=2.605, p=.010$, Cohen's $d=0.48)$, and skipped fewer anagrams $(t(121)=9.396$, $p<.001$ Cohen's $d=1.87$ ). Table 3 presents the means for the very easy and challenging anagram conditions.

We then replicated the effects of song order and task difficulty using a $3 \times 2$ mixed-model ANOVA. We found a main effect of song order $(F(2,242)=34.705$, $M S E=469.941, p<.001$, partial $\left.e t a^{2}=.223\right)$, a main effect of anagram difficulty $(F(1,121)=5.434, M S E=573.642$, $p=.021$, partial $\left.e t a^{2}=.043\right)$, and a significant interaction $\left(F(2,242)=3.548, M S E=469.941, p=.030\right.$, partial eta $\left.^{2}=.028\right)$. We used Tukey's simple effect comparisons to investigate the interaction and main effects. We found that the third song replayed for a greater percentage of the task than either the first or second songs in both the easy and challenging conditions. In addition, we found that the third song replayed mentally for a greater percentage of the time for participants in the challenging anagram condition than for those in the easy condition but no difference between the easy and challenging conditions for the first and second songs. Figure 2(b) displays the mean percentage of time that the songs replayed in both anagram conditions.

We again looked for a Zeigarnik effect on the basis of whether participants who had the song playing in their heads during the experiment were more likely to have the song return during the next day. We replicated that effect such that if participants reported the third song replaying during the anagrams they were more likely to have an intrusive song experience in the next 24 hours $(62.1 \%)$ than if they had not had the song mentally replaying $(25.0 \%), \chi^{2}(1, N=49)=6.530$, $p=.011$.

We designed Study 5 as a replication of Study 4 to allow a cross-experiment comparison of intrusive songs on the basis of not only cognitive load but also the nature of the cognitive task. Thus, we computed a $2 \times 2$ ANOVA looking at the effects of task difficulty (easy vs challenging) and puzzle type (Sudoku vs anagram) on the percentage of time that the third song replayed during the puzzle task. We found a main effect of task difficulty $(F(1,258)=16.687$, $M S E=1064.460, p<.001$, partial $\left.e t a^{2}=.061\right)$, a main effect of puzzle type $(F(1,258)=6.933, M S E=1064.460, p=.009$, partial $\left.e^{2} a^{2}=.026\right)$, and no interaction, $(F(1,258)=0.312$, $M S E=1064.460, p=.577$, partial $\left.e t a^{2}=.001\right)$. We found that participants experienced the third song less when completing verbal tasks (anagrams) than nonverbal tasks (Sudoku). This is consistent with the finding of Smith et al (1995) that auditory imagery involves the phonological loop aspect of working memory.

\section{GENERAL DISCUSSION}

Having a song stuck in your head is a commonly experienced intrusive thought. We conducted a survey about the experience and developed a methodology for creating and manipulating intrusive song experiences. We found that intrusive songs may share characteristics with other intrusive thoughts and involuntary memories. Intrusive songs occur for both liked and disliked songs just as involuntary and intrusive memories occur for both positive and negative experiences (Berntsen, 1996; Berntsen, 2001; Brewin et al., 1996). Similar to other surveys of intrusive songs (Beaman \& Williams, 2010; 
Halpern \& Bartlett, 2011), we found that intrusive songs occurred more frequently for liked than disliked songs. This contradicts the myth that obnoxious songs are more commonly stuck in one's head. However, we are not convinced that liking a song causes intrusive song experiences. Instead, people may listen to and know songs that they like. Thus, recent exposure and familiarity may be the proximate causes of intrusive song cycles. In our survey, the most commonly reported cause of intrusive song experiences was recent exposure, replicating Kvavilashvili and Mandler (2004) and Williamson et al. (2012). Kvavilashvili and Mandler argued that this may be a form of priming.

Involuntary memories often occur in response to environmental cues (Berntsen, 1996; Berntsen, 2001; Mace, 2005). Similarly, we found that intrusive songs may reflect various forms of cuing. In our survey, people reported various cues leading to intrusive song experiences. In the diary study, thinking of class often led the song to return. We also found, however, that in some cases people could not report any specific cue. At this point, it is unclear whether intrusive songs sometimes occur without external cuing or if people simply fail to notice and remember cues (Kvavilashvili \& Mandler, 2004; Williamson et al., 2012).

We found that people reexperience many musical features when an intrusive song returns to consciousness. People also report reexperiencing for involuntary autobiographical memories (Rasmussen \& Berntsen, 2009) and involuntary memories of aversive pictures (Hall \& Berntsen, 2008). But as Berntsen and her colleagues have argued, reexperiencing may be a component of both voluntary and involuntary memories (Hall \& Berntsen, 2008; Rasmussen \& Berntsen, 2009). Because people also reexperience many music features when they intentionally imagine music (Bailes, 2007; Halpern, 1988a; Halpern, 1988b; Levitin, 1994; Lucas et al., 2010), reexperiencing may be a feature of conscious experience rather than intrusive thoughts.

In all of our studies, people acknowledged two repetitive characteristics of intrusive songs. First, only a small part of the song typically repeats. One possible explanation is that working memory only holds a limited amount of auditory material (Smith et al., 1995). However, Beaman and Williams (2010) argued that the repeating portion of a song is often longer than should fit in working memory, implying that it is being retrieved from long-term memory. In that case, the inability to reconstruct entire songs may explain why only a portion of the song repeats (Hyman \& Rubin, 1990; Rubin, 1995). For example, a person may begin experiencing an intrusive song, continue through the parts that are strongly connected, and then experience difficulty leaping across the gap from the chorus to a subsequent verse. The chorus may then start to loop repetitively.

The second repetitive characteristic of intrusive songs is that they return to awareness after disappearing for a time. In our survey, people reported experiencing intrusive songs intermittently rather than constantly. In both the diary study and all three lab experiments, if a song continued to play in someone's head shortly after hearing it, then the song was likely to return again later. Exactly why an intrusive thought can apparently leave consciousness but then return repetitively is unclear. Mace (2005) argued that being exposed to an intrusive thought primed the experience (see also Kvavilashvili \& Mandler, 2004). The thought could then be reactivated with weaker cues. Because intrusive songs also returned during periods of low cognitive load, such as walking, the songs may have returned without explicit cues. Potentially, the songs never completely lost activation and returned to the center of awareness when other thoughts no longer occupied the center of consciousness. Both repetitive characteristics may be similar to intrusive memories in which part of an autobiographical experience may repetitively return to consciousness.

With our findings and other recent surveys (Beaman \& Williams, 2010; Halpern \& Bartlett, 2011; Liikkanen, 2012a, 2012b; Williamson et al., 2012), we can suggest a possible outline of how intrusive songs occur. First, a person must know the song fairly well. Hearing a song may lead to the music continuing in someone's head after the song has stopped playing but may not be enough to begin an intrusive song cycle. For a song to return to awareness, it must be well known and stored in long-term memory. Similar to other researchers (Beaman \& Williams, 2010; Halpern \& Bartlett, 2011), we found that liked songs more frequently become intrusive. This may reflect opportunity-people are more frequently exposed to songs they like.

Second, intrusive songs frequently reflect environmental priming and cuing. Listening to a known song is often enough to start an intrusive song cycle. But other cues, such as hearing words that remind a person of song lyrics, may bring the song to mind (Williamson et al., 2012). Once an intrusive song cycle has begun, the strength of cue needed to bring a song back may be reduced. The song may be primed by recent exposure and waiting for any relevant cue to reenter awareness (see Mace, 2005).

Finally, intrusive songs often return to awareness during periods of low cognitive load and, as we found in Studies 4 and 5, during cognitively challenging activities. Of course, it appears contradictory to argue that both low and high cognitive loads may lead to intrusive songs. On both ends of the spectrum, however, people may be less engaged in their primary activity and leave more cognitive resources for other thoughts to enter consciousness. Thus, intrusive songs, and other intrusive thoughts, may be common during periods of cognitive inactivity and boredom or when the mind is struggling with a difficult activity. For these reasons, intrusive songs may be related to mind wandering (Kane et al., 2007; McVay \& Kane, 2010; Schooler, 2002; Smallwood \& Schooler, 2006). Our findings in Studies 4 and 5 also suggest a method for limiting intrusive thoughts and involuntary memories. We found that people experienced the intrusive songs less frequently when they were successfully engaged in an appropriately challenging cognitive task. If the mind is fully engaged, then there may be fewer cognitive resources remaining for intrusive thoughts.

Undoubtedly, other factors are involved in the experience of intrusive songs. Using our experimental method, we will investigate how cognitive load during both exposure and subsequent activities influences the onset of intrusive song cycles. We will also investigate whether attempts to suppress a song will make the song more likely to return (Beaman \& Williams, 2010; Wegner, Schneider, Carter, \& White, 1987). 
Additionally, the nature of the song and individual differences may contribute to intrusive song cycles (Kellaris, 2008; Levitin, 2006; Liikkanen, 2012a; Sacks, 2007).

Throughout this paper, we have referred to the experience of having a song stuck in one's head as an intrusive song. Others have referred to the experience as involuntary musical imagery (Liikkanen, 2008, 2012a; Sacks, 2007). Both intrusive and involuntary have been used to describe autobiographical memories that come to mind spontaneously, without volitional control. At this point, researchers have not settled on a clear definitional difference between intrusive and involuntary. Kvavilashvili and Schlagman (2011) recently suggested that a key feature of intrusive memories may be that the memories come to mind repetitively, whereas most involuntary memories come to mind on one occasion. Repetitiveness is clearly a continuum because involuntary memories vary in terms of how frequently they come to mind and because more strongly emotional involuntary memories, both positive and negative, are more likely to have been experienced repetitively (Berntsen, 2001). Clearly, songs stuck in the head are often experienced repetitively. In our survey, people reported hearing the song intermittently, and in all of our experimental studies, if a song began playing in someone's head, it was very likely to return later. Thus, intrusive rather than involuntary may be the correct term to describe having a song stuck in one's head. Of course, other features may also distinguish the intrusive subcategory of involuntary thoughts and memories. For example, people may find intrusive memories to be more disruptive and may try to actively avoid the memories. At this point, it is unclear to what extent intrusive songs are disruptive or if people actively work to avoid thinking about intrusive songs.

Involuntary and intrusive thoughts may be a hallmark of conscious experience rather than a response to traumatic events (Berntsen, 1996; Brewin et al., 1996; Rasmussen \& Berntsen, 2009). Thoughts come to mind for a variety of reasons. Sometimes, we intentionally bring a fact, memory, or song to mind. Other times, a thought enters awareness without volitional control. Songs frequently come to mind as intrusive thoughts, and intrusive song cycles are easy to start in both naturalistic and laboratory situations. In our experimental studies, we have documented that intrusive song cycles are easy to start and manipulate. Therefore, songs may provide a valuable tool for examining why intrusive thoughts occur and how to control intrusive thought cycles.

\section{ACKNOWLEDGEMENT}

We thank the students who helped conduct the research, particularly those who worked as researcher-participants in the diary study.

\section{REFERENCES}

Antrobus, J. S., Singer, J. L., \& Greenberg, S. (1966). Studies in the stream of consciousness: Experimental enhancement and suppression of spontaneous cognitive processes. Perceptual and Motor Skills, 23, 399-417.
Bailes, F. (2007). The prevalence and nature of imagined music in the everyday lives of music students. Psychology of Music, 35, 555-570. DOI: 10.1177/ 0305735607077834

Beaman, C. P., \& Williams, T. I. (2010). Earworms ('stuck song syndrome'): Towards a natural history of intrusive thoughts. British Journal of Psychology, 101, 637-653. DOI: 10.1348/000712609X479636

Becker, S. S., Horowitz, M. J., \& Campbell, L. (1973). Cognitive responses to stress: Effects of changes in demand and sex. Journal of Abnormal Psychology, 82, 519-522.

Berntsen, D. (1996). Involuntary autobiographical memories. Applied Cognitive Psychology, 10, 435-454.

Berntsen, D. (2001). Involuntary memories of emotional events: Do memories of traumas and extremely happy events differ? Applied Cognitive Psychology, 15, S135-S158. DOI: 10.1002/acp.838

Brewin, C. R., Christodoulides, J., \& Hutchinson, G. (1996). Intrusive thoughts and intrusive memories in a nonclinical sample. Cognition and Emotion, 10, 107-112.

Hall, N. M., \& Berntsen, D. (2008). The effect of emotional stress on involuntary and voluntary conscious memories. Memory, 16, 48-57. DOI: 10.1080/0965210701333271

Halpern, A. R. (1988a). Mental scanning in auditory imagery for songs. Journal of Experimental Psychology: Learning, Memory, and Cognition, 14, 434-443.

Halpern, A. R. (1988b). Perceived and imagined tempos of familiar songs. Music Perception, 6, 193-202.

Halpern, A. R., \& Bartlett, J. C. (2011). The persistence of musical memories: A descriptive study of earworms. Music Perception, 28, 425-431. DOI: $10.1525 / \mathrm{mp} .2011 .28 .1 .425$

Halpern, A. R., \& Zatorre, R. J. (1999). When that tune runs through your head: A PET investigation of auditory imagery for familiar melodies. Cerebral Cortex, 9, 697-704. DOI: 10.1093/cercor/9.7.697

Halpern, A. R., Zatorre, R. J., Bouffard, M., \& Johnson, J. A. (2004). Behavioral and neural correlates of perceived and imagined musical timbre. Neuropsychologia, 42, 1281-1292. DOI: 10.1016/j.neuropsychologia. 2003.12.017

Holmes, E. A., \& Bourne, C. (2008). Inducing and modulating intrusive emotional memories: A review of the trauma film paradigm. Acta Psychologica, 127, 553-566.

Horowitz, M. J., \& Becker, S. S. (1971). The compulsion to repeat trauma. The Journal of Nervous and Mental Disease, 153, 32-40.

Horowitz, M. J., \& Becker, S. S. (1973a). Cognitive response to stress and experimental demand. Journal of Abnormal Psychology, 78, 86-92.

Horowitz, M. J., \& Becker, S. S. (1973b). Cognitive response to erotic and stressful films. Archives of General Psychiatry, 29, 81-84.

Hyman, Jr., I. E., \& Rubin, D. C. (1990). Memorabeatlia: A naturalistic study of long-term memory. Memory \& Cognition, 18, 205-214.

Kane, M. J., Brown, L. H., McVay, J. C., Silvia, P. J., Myin-Gerneys, I., \& Kwapil, T. R. (2007). For whom the mind wanders, and when: An experience-sampling study of working memory and executive control in daily life. Psychological Science, 18, 614-621.

Kellaris, J. J. (2003). Dissecting earworms: Further evidence on the 'songstuck-in-your-head' phenomenon. In C. Page, \& S. Posavac (Eds.), Proceedings of the Society for Consumer Psychology Winter Conference (pp. 220-222). Potsdam, NY: Society for Consumer Psychology.

Kellaris, J. J. (2008). Music and consumers. In C. P. Haugtvedt, P. Herr, \& F. R. Kardes (Eds.), Handbook of consumer psychology (pp. 837-856). New York: Taylor \& Francis.

Kelley, C. M., \& Jacoby, L. L. (1996). Adult egocentrism: Subjective experience versus analytic bases for judgment. Journal of Memory and Language, 35, 157-175.

Klos, D. S., \& Singer, J. L. (1981). Determinants of the adolescent's ongoing thought following simulated parental confrontations. Journal of Personality and Social Psychology, 41, 975-987.

Kvavilashvili, L., \& Mandler, G. (2004). Out of one's mind: A study of involuntary semantic memories. Cognitive Psychology, 48, 47-94.

Kvavilashvili, L., \& Schlagman, S. (2011). Involuntary autobiographical memories in dysphoric mood: A laboratory study. Memory, 19, 331-345.

Levitin, D. J. (1994). Absolute memory for musical pitch: Evidence from the production of learned melodies. Perception \& Psychophysics, $56,414-423$.

Levitin, D. J. (2006). This is your brain on music: The science of a human obsession. New York, NY: Plume. 
Liikkanen, L. A. (2008). Music in every mind: Commonality of involuntary musical imagery. In K. Miyazaki, Y. Hiraga, M. Adachi, Y. Nakajima, \& M. Tsuzaki (Eds.), Proceedings of the 10th International Conference on Music Perception and Cognition (pp. 408-412). Sapporo, Japan: ICMPC.

Liikkanen, L. A. (2012a). Musical activities predispose to involuntary musical imagery. Psychology of Music, 40, 236-256. DOI: $10.1177 /$ 0305735611406578

Liikkanen, L. A. (2012b). Inducing involuntary musical imagery: An experimental study. Musicae Scientiae. Advance online publication. DOI: $10.1177 / 1029864912440770$

Lucas, B. J., Schubert, E., \& Halpern, A. R. (2010). Perception of emotion in sounded and imagined music. Music Perception, 27, 399-412.

Mace, J. H. (2005). Priming involuntary autobiographical memories. Memory, 13, 874-884. DOI: 10.1080/09658210444000485

McVay, J. C., \& Kane, M. J. (2010). Does mind wandering reflect executive function or executive failure? Comment on Smallwood and Schooler (2006) and Watkins (2008). Psychological Bulletin, 136, 188-197. DOI: $10.1037 / \mathrm{a} 0018298$

Rasmussen, A. S., \& Berntsen, D. (2009). The possible functions of involuntary autobiographical memories. Applied Cognitive Psychology, 23, 1137-1152. DOI: 10.1002/acp.1615

Rubin, D. C. (1995). Memory in oral traditions: The cognitive psychology of epic, ballads, and counting-out rhymes. New York, NY: Oxford University Press.

Sacks, O. (2007). Musicophilia: Tales of music and the brain. New York, NY: Vintage Books.
Schooler, J. W. (2002). Re-representing consciousness: Dissociations between experience and meta-consciousness. Trends in Cognitive Sciences, 6, 339-344. DOI: 10.1016/S1364-6613(02)01949-6

Smallwood, J., \& Schooler, J. W. (2006). The restless mind. Psychological Bulletin, 132, 946-958. DOI: 10.1037/0033-2909.132.6.946

Smallwood, J., Nind, L., \& O'Connor, R. C. (2009). When is your head at? An exploration of the factors associated with the temporal focus of the wandering mind. Consciousness and Cognition, 18, 118-125. DOI: 10.1016/j.concog.2008.11.004

Smith, J. D., Wilson, M., \& Reisberg, D. (1995). The role of subvocalization in auditory imagery. Neuropsychologia, 33, 1433-1454.

Wammes, M., \& Baruss, I. (2009). Characteristics of spontaneous musical imagery. Journal of Consciousness Studies, 16, 37-61.

Wegner, D. M., Schneider, D. J., Carter, III, S. R., \& White, T. L. (1987). Paradoxical effects of thought suppression. Journal of Personality and Social Psychology, 53, 5-13.

Williamson, V. J., Jilka, S. R., Fry, J., Finkel, S., Mullensiefen, D., \& Stewart L. (2012). How do "earworms" start? Classifying the everyday circumstances of involuntary musical imagery. Psychology of Music, 40, 259-281. DOI: 10.1177/0305735611418553.

Zatorre, R. J., Halpern, A. R., Perry, D. W., Meyer, E., \& Evans, A. C. (1996). Hearing in the mind's ear: A PET investigation of musical imagery and perception. Journal of Cognitive Neuroscience, 8, 29-46. DOI: 10.1162/jocn.1996.8.1.29

Zeigarnik, B. (1967). On finished and unfinished tasks. In W. D. Ellis (Ed.), A source book of Gestalt psychology (pp. 300-314). London, England: Kegan, Paul, Trench, Trubner \& Company. 